\title{
PRODUÇÃO ACADÊMICA DOS TEMAS GOVERNANÇA CORPORATIVA E SUSTENTABILIDADE: UMA ANÁLISE DOS ÚLTIMOS 14 ANOS NOS PERIÓDICOS INTERNACIONAIS
}

\section{ACADEMIC PRODUCTION ISSUES OF CORPORATE GOVERNANCE AND SUSTAINABILITY: AN ANALYSIS OF THE LAST 14 YEARS IN INTERNATIONAL JOURNALS}

\author{
Henrique César Melo Ribeiro \\ (Universidade Nove de Julho-SP e Faculdade Maurício de Nassau-Unidade Parnaíba-PI) \\ hcmribeiro@hotmail.com
}

Submissão: $22 / 09 / 2013$

Aprovação: 14/02/2014

\section{RESUMO}

Este artigo mapeou o perfil e a produção acadêmica dos temas Governança Corporativa e Sustentabilidade em conjunto, durante o período de 2000 a 2013, nos periódicos internacionais nas áreas de Administração, Contabilidade, Economia, Finanças e Turismo. Metodologicamente, utilizaram-se as técnicas de análise bibliométrica, como também a estatística descritiva nos 58 artigos identificados. Realça-se também que a análise de redes foi trabalhada também enfatizando os atributos de densidade e centralidade. Os principais resultados foram: aproximadamente $69 \%$ das publicações foram realizadas em parceria; Anwar, Cvelbar, Galbreath, Lazonick e Mulyadi foram os autores mais profícuos; as Universidades de Curtin e Cambridge foram as que mais publicaram; os países que se destacaram neste estudo foram Austrália, EUA e Inglaterra. Observou-se baixa densidade das redes sociais analisadas neste estudo. E os temas mais abordados foram a responsabilidade social corporativa, disclosure, valor aos acionistas, desempenho organizacional, conselho de administração, desenvolvimento sustentável, ética, auditoria e estrutura de capital.

Palavras-chave: Governança Corporativa. Sustentabilidade. Produção acadêmica. Periódicos internacionais. 
ABSTRACT

This article has mapped the profile and academic production of the Corporate Governance and Sustainability themes together, during the period 2000-2013, in international journals in the areas of Administration, Accounting, Economics, Finance and Tourism. Methodologically, we used the techniques of bibliometric analysis, as well as the descriptive statistics in the 58 articles identified. It is emphasized also that the network analysis was also worked emphasizing the attributes of density and centrality. The main results were: approximately $69 \%$ of the publications were conducted in partnership; Anwar, Cvelbar, Galbreath, Lazonick and Mulyadi, were the most prolific authors; the Universities of Cambridge and Curtin were those published more; countries that stood out in this study were Australia, USA and England. Observed a low density of social networks analyzed in this study. And the most discussed topics were the corporate social responsibility, disclosure, shareholder value, organizational performance, board, sustainable development, ethics, audit and capital structure.

Keywords: Corporate Governance. Sustainability. Academic procuction. International journals. 


\title{
1. Introdução
}

Em grande parte, a produção acadêmica é fruto de orientações de mestrado e doutorado (ROSSONI; HOCAYEN-DA-SILVA, 2008). Neste panorama, Souza, Silva e Araújo afirmam que:

\begin{abstract}
A produção científica é na atualidade uma das maiores ferramentas de desenvolvimento de uma sociedade, sendo utilizada para a busca dos questionamentos que a população julga como fundamentais para o bom convívio em grupo. Associado a esse fato, tem-se que os artigos publicados em periódicos são um dos atores principais para a se atingir esse objetivo da comunicação científica, em virtude de seus resultados serem apresentados para a população de maneira mais rápida e por atingirem um grupo maior de pessoas, devido à facilidade de divulgação e circulação dos periódicos. (2012, p. 4)
\end{abstract}

Neste contexto, ressalva-se que, para a determinação do perfil de uma produção científica é necessário analisar diversos estudos publicados em determinada(s) área(s) para se identificar suas características (COSTA; BOENTE, 2012). Esta ação se faz necessária, pois os temas Governança Corporativa e Sustentabilidade são campos importantes de pesquisa. Contudo, quando se analisa as duas áreas juntas, mediante sua produção acadêmica, não se encontraram publicações sobre tal, fazendo com que fosse preciso preencher este vazio na literatura acadêmica.

Diante disso, foi elaborada a questão de pesquisa que norteou este estudo: qual o perfil e a produção acadêmica dos assuntos Governança Corporativa e Sustentabilidade em conjunto, nos dos periódicos internacionais das áreas de Administração, Contabilidade, Economia, Finanças e Turismo? Sob esta ótica, este trabalho tem o objetivo de mapear o perfil e a produção acadêmica dos temas Governança Corporativa e Sustentabilidade em conjunto, durante o período de 2000 a 2013. Justifica-se fazer este estudo por entender e constatar que a Governança Corporativa tem uma ampla relação com a Sustentabilidade, ou seja, nos aspectos econômico, ambiental e social (KOCMANOVÁ; HŘEBÍČEK; DOČEKALOVÁ, 2011).

Com isso, este paper contribuirá para a relevância da pesquisa nas áreas ora mapeadas, fomentando, aperfeiçoando, disseminando, socializando e divulgando a produção acadêmica sobre os temas, fazendo com que possam surgir novos pesquisadores, contribuindo a posteriori para o aparecimento ou otimização de grupos 
de pesquisa sobre estes temas. Outra contribuição deste estudo é entender a importância que a Governança Corporativa tem como tema horizontal na literatura acadêmica internacional, ou seja, sua importância intrínseca no aperfeiçoamento e entendimento de temas inerentes à mesma, como é o caso da Sustentabilidade (ELKINGTON, 2006).

Este estudo está subdivido em cinco sessões. A primeira contempla a introdução, justificativa, questão, objetivo e contribuição deste estudo. A segunda sessão evidencia a fundamentação, a qual aborda a relação dos temas Governança Corporativa e Sustentabilidade, por meio de estudos acadêmicos. A seguir vêm os procedimentos metodológicos. A quarta sessão vislumbra a análise dos resultados. E por fim realça-se a discussão e as considerações finais, com as limitações e sugestões para futuras pesquisas.

\section{Governança Corporativa e Sustentabilidade}

A Governança Corporativa é o conjunto de regras, práticas (CASTRO JUNIOR; CONCEIÇÃO; SANTOS, 2011), e instituições que determinam como os gestores agem no melhor interesse das partes envolvidas nos negócios da organização, em especial os acionistas (LEAL; SAITO, 2003), criando valor aos mesmos (STAUB; MARTINS; RODRIGUES, 2002). Tem papel preponderante na minimização dos conflitos de agência (COELHO; LOPES, 2007) por meio de seus mecanismos (conselho de administração e estrutura de propriedade) (SILVEIRA; BARROS; FAMÁ, 2003) e seus princípios (TERRA; LIMA, 2006), que são: transparência, prestação de contas, equidade, ética e responsabilidade corporativa (Sustentabilidade) (MALACRIDA; YAMAMOTO, 2006; BERARDI, 2008).

Realça-se aqui a interdisciplinaridade do tema Governança Corporativa com outras temáticas (RIBEIRO et al., 2012a), inclusive com o assunto Sustentabilidade (HEINZMANN; DREHER, 2012). Pode-se afirmar que a Governança Corporativa e a Sustentabilidade são as expressões da moda nos dias de hoje, tanto no âmbito empresarial como no acadêmico (ÁLVARES; GIACOMETTI; GUSSO, 2008). Em outras palavras, o tema Governança Corporativa caracteriza-se pelo relacionamento estratégico calcado na Sustentabilidade (BERTUCCI; BERNARDES; BRANDÃO, 2006), principalmente no ambiente dos conselhos de administração (STEINBERG, 
2008), estimulando assim a responsabilidade social corporativa (SCHROEDER; SCHROEDER, 2004; NUNES et al., 2010).

Neste panorama, realça-se que com o objetivo de oferecer ao mercado de capitais um índice para mensurar iniciativas de organizações comprometidas com a responsabilidade social e a Sustentabilidade e que sejam promotoras das boas práticas de Governança Corporativa no Brasil, a BM\&F Bovespa, em $1^{\circ}$ de dezembro de 2005 , lançou o Índice de Sustentabilidade Empresarial (ISE). Este indicador tem como eixo a Governança Corporativa (GALLON; ENSSLIN, 2008). O conceito do ISE é o Triple Bottom Line, que avalia os elementos, econômico, ambiental e social, e a estes atributos foram acrescentados critérios e indicadores de Governança Corporativa, fomentando assim o ISE (BASSETTO, 2010).

A Sustentabilidade diz respeito a buscar o lucro responsável, inovar em produtos e processos e ter boas práticas de Governança Corporativa (SROUR, 2011). Diante do exposto, é salutar afirmar que a Sustentabilidade associa-se diretamente com a Governança Corporativa, o que pode ser constatado quando se observa os princípios balizadores das boas práticas, ética, transparência, equidade, prestação de contas e responsabilidade social corporativa (LOPES; BERNARDES; LARA, 2009; SILVA; REIS; AMÂNCIO, 2011; LEITE et al., 2013), sobretudo quando se enfatiza a ética, princípio este inerente à Sustentabilidade, ajudando assim a melhor entender a fusão da Governança Corporativa com as preocupações sustentáveis (ELKINGTON, 2006).

Em suma, a Governança Corporativa é um elemento chave para que as empresas consigam melhor desempenho, e junto com a Sustentabilidade, que pode ser entendida como uma estratégia corporativa, a performance e a competividade das organizações costumam aumentar, ou seja, a Governança Corporativa, ao incorporar os aspectos econômico, ambiental e social, é essencial para a criação de valor das empresas (KOCMANOVÁ; HŘEBÍČEK; DOČEKALOVÁ, 2011). Verifica-se aí uma forte interação entre Governança Corporativa e a Sustentabilidade, pois ambas são fundamentais para a continuidade de qualquer organização (ARAS; CROWTHER, 2008), servindo também como mecanismos legitimados que as empresas utilizam para se comunicar com seus stakeholders (MICHELON; PARBONETTI, 2012).

Diante do que foi relatado até agora, observa-se que os temas Governança Corporativa e Sustentabilidade podem ser considerados intrínsecos no meio da gestão e 
como campos de estudos importantes para a academia. Contudo, os trabalhos bibliométricos de publicações sobre Governança Corporativa e ou Sustentabilidade são recentes. Esta constatação deu-se em virtude das buscas destas pesquisas para aperfeiçoar, no que se refere à comparação das informações evidenciadas neste estudo com as informações geradas por outros trabalhos correlatos.

Com isso, realçam-se os estudos nacionais e internacionais bibliométricos sobre os assuntos Governança Corporativa: Durisin e Puzone (2009), Souza e Borba (2009), Catapan e Cherobim (2011), Huang e Ho (2011), Duarte, Cardozo e Vicente (2012), Ribeiro et al. (2012a), Ribeiro et al. (2012b), Ribeiro, Muritiba e Muritiba (2012), Dal Vesco e Beuren (2012), Da Cunha, Moura e Santana (2013), Pinheiro, Carrieri e Joaquim (2013), Ribeiro, Costa e Ferreira (2013) e Ribeiro et al. (2013).

E Sustentabilidade: Yarime, Takeda e Kajikawa (2010), Gabriele et al. (2012), Romo-Fernández, Guerrero-Bote e Moya-Anegón (2012), Schoolman et al. (2012), Catapan et al. (2013), Jabbour et al. (2013), Machado Júnior et al. (2013), Schmitt, Hayde e Dreher (2013) e Souza e Ribeiro (2013).

Estas pesquisas nacionais e internacionais bibliométricas de Governança Corporativa e Sustentabilidade mostram, assim, a emergência dos dois temas na academia. Contudo, só foi registrado o encontro de apenas um estudo que evidenciasse a produção científica das temáticas em conjunto.

Os autores Heinzmann e Dreher (2012), analisaram a produção científica nacional sobre Governança Corporativa e Sustentabilidade. Eles analisaram a referida produção mediante os anais dos eventos EnANPAD, EnEO, 3Es, EMA, EnADI, EnAPG, EnGPR e Engema no período de 2002 a 2009. Os principais resultados encontrados pelos pesquisadores foram: foram encontrados somente 26 estudos sobre os dois temas juntos; o evento EnANPAD foi o que mais publicou; predominância de estudos publicados em parceria; a Universidade Federal de Campina Grande foi a mais prolífica; sete autores se destacaram por sua proficuidade; são eles: Bruni, Lemme, Campos, Costa, Rezende, Nunes e Cavalcante. Em suma, os articulistas constataram que as publicações científicas sobre os temas Governança Corporativa e Sustentabilidade estão concentradas em um pequeno número de autores, ou seja, existe pouca incidência de discussão acadêmica destas duas temáticas em conjunto. 
Observou-se que os temas Governança Corporativa e Sustentabilidade são inerentes e são emergentes na academia, tanto nas pesquisas bibliométricas no contexto individual, como em especial nas publicações bibliométricas, quando os dois assuntos se unem. Diante do exposto, esta pesquisa contribuirá para fomentar, aperfeiçoar, disseminar, socializar e divulgar, por meio das publicações internacionais nas áreas de Administração, Contabilidade, Economia, Finanças e Turismo, durante o período de 2000 a 2013, a junção dos temas Governança Corporativa e Sustentabilidade na literatura acadêmica nacional, contribuindo também para mitigar possíveis gaps que poderiam existir até hoje.

\section{Procedimentos metodológicos}

O objetivo desta pesquisa foi mapear o perfil e a produção acadêmica dos temas Governança Corporativa e Sustentabilidade em conjunto, durante o período de 2000 a 2013, nos periódicos internacionais nas áreas de Administração, Contabilidade, Economia, Finanças e Turismo. Para isso utilizou-se as técnicas de análise bibliométrica (CARDOSO et al., 2005) e de redes sociais (MIZRUCHI, 2006).

A análise bibliométrica é parte preponderante do processo de compreensão da ciência (ROCZANSKI et al., 2010) e é considerada uma técnica para o mapeamento dos principais autores, periódicos e palavras-chave, ajudando a compreender os temas abordados (HENRIQUES; SELIG; MIGUEL, 2012). E, portanto, foi escolhido com um dos instrumentos de intervenção para o levantamento de indicadores relativos à produção científica (IGARASHI et al., 2008) sobre os temas Governança Corporativa e Sustentabilidade.

Salienta-se que as leis da bibliometria - Zipf (frequência de palavras), Lotka (produtividade de autores) e Bradford (produtividade de periódicos) (PINHEIRO, 1983) - serão essenciais para melhor compreensão das informações mensuradas neste estudo.

A Lei de Zipf realça a frequência com que palavras aparecem, ou seja, o número de ocorrência destas palavras nos textos (QUONIAM et al., 2001), sendo que neste estudo esta Lei é evidenciada e verificada por meio da Figura 7. Já a Lei de Lotka evidencia a produtividade dos pesquisadores (CARDOSO et al., 2005), contemplada aqui na Tabela 3. E, por fim, a Lei de Bradford sugere que à medida que os primeiros trabalhos sobre novo(s) tema(s) são escritos, eles são submetidos a uma pequena 
seleção, por revistas apropriadas, e se aceitos essas revistas convidam mais e mais papers, no decorrer do desenvolvimento da área/assunto/tema. Ao mesmo tempo, outras revistas publicam seus primeiros estudos sobre o tema. Se o tema continuar a crescer, emerge eventualmente um núcleo de revistas, que corresponde aos journals mais produtivos, em termos de artigos publicados, sobre esta(s) temática(s) (BEUREN; SOUZA, 2008). E isto é evidenciado na Tabela 1 deste estudo.

O outro instrumento foi a Análise de Redes Sociais, que é essencial para se identificar os atores mais relevantes em uma rede social (ROSSONI et al., 2007), e seus laços por eles mantidos socialmente em forma de elos (SAMPAIO; ROSA; PEREIRA, 2012). Portanto, a Análise de Redes Sociais será uma ferramenta bastante adequada e suficientemente estruturada, capaz de entender as incursões da produção científica dos temas Governança Corporativa e Sustentabilidade.

É importante ressaltar que na Análise de Redes Sociais o conceito de densidade é essencial, pois resume todas as distribuições de links para mensurar a distância entre as posições ocupadas, indicando o nível de articulação entre os atores envolvidos na rede social (CRUZ et al., 2011). É importante também ter a noção do que é a centralidade, pois é frequentemente usada nas Análises de Rede. Entende-se com isso que quanto mais centrais mais importantes são determinados atores em uma rede. Três são as medidas comumente utilizadas para esta avaliação: centralidade de grau (degree), centralidade de proximidade (closeness) e a centralidade de intermediação (betweenness) (ROSSONI; GUARIDO FILHO, 2009).

Para mapear o perfil e a produção acadêmica dos temas Governança Corporativa e Sustentabilidade em conjunto, foi realizada uma coleta de dados em artigos publicados no período de 2000 a 2013, o que corresponde a um levantamento longitudinal de 14 anos. Os dados foram coletados do ISI Web of Science (acessível em <isiknowledge.com>). O critério utilizado para a busca e seleção dos artigos relevantes nos periódicos internacionais da área de Administração, Contabilidade, Economia, Finanças e Turismo incluídos na base de dados do ISI envolveu as duas palavras-chave: corporate governance e sustainability. As palavras-chave foram pesquisadas simultaneamente, de modo a identificar artigos que incluíssem as duas palavras, e não cada uma separadamente. Este procedimento permitiu identificar 35 periódicos 
internacionais que publicaram artigos relevantes para a amostra. A amostra final foi composta por 58 artigos publicados no período 2000-2013.

As análises efetuadas sobre a amostra de 58 artigos foram realizadas mediante as seguintes variáveis: (I) produção acadêmica dos temas; (II) periódicos de destaque; (III) autoria; (IV) autores; (V) IESs; (VI) países; (VII) redes de coautoria; (VIII) redes das IESs; (IX) redes dos países; (X) redes dos autores e IESs; (XI) redes das IESs e países; (XII) palavras-chave; e (XIII) temas abordados. Os dados foram coletados usando o software Bibexcel e as representações das redes, inclusive as redes two-mode (modo-duplo) foram feitas usando o software Ucinet 6. Salienta-se que estas redes two-mode caracterizam-se por ter dois conjuntos distintos de atores, com atributos particulares para cada conjunto (MATHEUS; SILVA, 2006).

\section{Análise dos resultados}

A Figura 1 evidencia a quantidade de artigos publicados sobre os temas Governança Corporativa e Sustentabilidade em conjuntos durante o período de 2000 a 2013.

Figura 1 - Produção acadêmica dos temas Governança Corporativa e Sustentabilidade

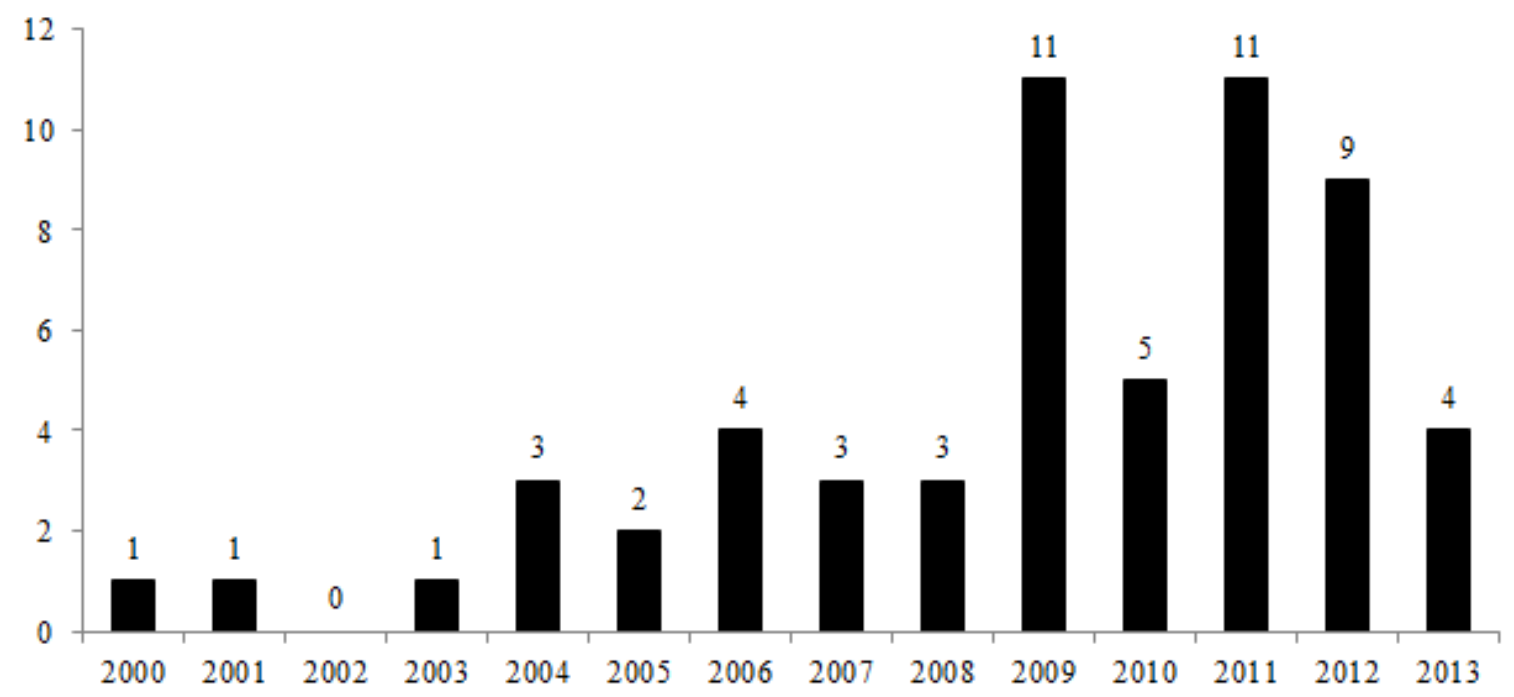

Fonte: Dados da pesquisa.

Analisando a Figura 1, observa-se que as pesquisas sobre os temas ora em investigação eram bem insipientes no início da década de 2000, só começando a crescer a partir do ano de 2006, alcançando seu pico nos períodos de 2009 e 2011, nos 
periódicos internacionais. Tal resultado pode ser em virtude do lançamento do ISE, que ocorrera no final de 2005 , e se caracteriza por ser um índice que tem como eixo a Governança Corporativa (GALLON; ENSSLIN, 2008).

No que tange aos periódicos internacionais, a Tabela 1 divulga as revistas que mais publicaram artigos em 14 anos de estudos.

Tabela 1 - Principais periódicos e seus respectivos fatores de impacto

\begin{tabular}{lcc}
\hline \multicolumn{1}{c}{ Periódicos } & Fator de Impacto & Artigos \\
\hline Corporate Governance: An International Review & 1.4 & 8 \\
\hline Journal of Business Ethics & 1.270 & 7 \\
\hline Management Decision & 1.3 & 4 \\
\hline Geneva Papers on Risk and Insurance-Issues and Practice & 0.382 & 3 \\
\hline African Journal of Business Management & 0.2 & 2 \\
\hline Australian Accounting Review & 0.833 & 2 \\
\hline Corporate Social Responsibility and Environmental Management & 1.69 & 2 \\
\hline International Journal of Technology Management & 0.52 & 2 \\
\hline Journal of Management \& Organization & 0.39 & 2 \\
\hline 26 periódicos publicaram 1 artigo & & 1 \\
\hline Fonte: Dados da pesquisa. & &
\end{tabular}

Constata-se que a revista Corporate Governance: an International Review foi a que mais produziu artigos sobre os assuntos em estudo, com oito publicações. Em seguida aparece o Journal of Business Ethics, com sete artigos publicados. Salientam-se também os journals: Management Decision e Geneva Papers on Risk and InsuranceIssues and Practice, com quarto e três manuscritos publicados.

É interessante notar que as duas primeiras revistas em destaque, ou seja, a Corporate Governance: an International Review e o Journal of Business Ethics, são periódicos de alto fator de impacto, sendo considerados preponderantes para os temas Governança e Ética na literatura acadêmica internacional. É importante salientar que a Ética é um princípio inerente à Sustentabilidade e que, portanto, ajuda a melhor compreender a fusão da Governança Corporativa com o desenvolvimento sustentável (ELKINGTON, 2006).

Realça-se que a revista Corporate Governance: an International Review aborda em sua essência temas relacionados especificamente sobre Governança Corporativa, sendo uma das pioneiras a atentar sobre o assunto e discutir questões de 
Governança Corporativa no mercado corporativo inglês (BERARDI, 2008). Já o Journal of Business Ethics pode ser classificado na categoria Ética, englobando também a Governança Corporativa, pois, esta é inerente à Ética, sendo exemplo disso o ISE da Bovespa (BERARDI, 2008). Em suma, as duas primeiras revistas, ao serem evidenciadas como as mais profícuas neste estudo sobre os temas Governança Corporativa e Sustentabilidade em conjunto, recebem este título por sua importância e pioneirismo na busca plena de fomentar, disseminar e socializar as questões inerentes aos temas Governança Corporativa e Ética, ou seja, a Sustentabilidade.

E com duas publicações as revistas African Journal of Business Management, Australian Accounting Review, Corporate Social Responsibility and Environmental Management, International Journal of Technology Management $e$ Journal of Management \& Organization. Salienta-se também que 26 periódicos publicaram apenas uma vez, o que equivale em percentual a 74,29\%.

Os 35 periódicos identificados neste estudo foram responsáveis por publicar 58 artigos relacionados aos temas Governança Corporativa e Sustentabilidade. E destes 58 papers, a maioria deles, ou seja, 68,97\%, foram publicados em parceria (vide Tabela $2)$, e destes a parceria de dois autores foi a predominante $(46,55 \%)$.

Tabela 2 - Autoria

\begin{tabular}{lcccccccccccccccc}
\hline Autoria/Ano & $\mathbf{0 0}$ & $\mathbf{0 1}$ & $\mathbf{0 2}$ & $\mathbf{0 3}$ & $\mathbf{0 4}$ & $\mathbf{0 5}$ & $\mathbf{0 6}$ & $\mathbf{0 7}$ & $\mathbf{0 8}$ & $\mathbf{0 9}$ & $\mathbf{1 0}$ & $\mathbf{1 1}$ & $\mathbf{1 2}$ & $\mathbf{1 3}$ & Total & $\mathbf{\%}$ \\
\hline Autoria única & & 1 & & & 2 & 1 & 1 & & & 5 & & 4 & 3 & 1 & 18 & 31,03 \\
\hline Dois autores & 1 & & & & 1 & 1 & 3 & 2 & 1 & 5 & 4 & 5 & 3 & 1 & 27 & 46,55 \\
\hline Três autores & & & & 1 & & & & 1 & 2 & 1 & 1 & 2 & 2 & 2 & 12 & 20,69 \\
\hline Cinco autores & & & & & & & & & & & & & 1 & & 1 & 1,72 \\
\hline Total & $\mathbf{1}$ & $\mathbf{1}$ & $\mathbf{0}$ & $\mathbf{1}$ & $\mathbf{3}$ & $\mathbf{2}$ & $\mathbf{4}$ & $\mathbf{3}$ & $\mathbf{3}$ & $\mathbf{1 1}$ & $\mathbf{5}$ & $\mathbf{1 1}$ & $\mathbf{9}$ & $\mathbf{4}$ & $\mathbf{5 8}$ & $\mathbf{1 0 0 , 0 0}$ \\
\hline
\end{tabular}

Fonte: Dados da pesquisa.

Ao constatar que as parcerias na publicação dos artigos de Governança Corporativa e Sustentabilidade em conjunto são predominantes e crescentes, observa-se o aparecimento e uma certa evolução de grupos de pesquisadores sobre as temáticas exploradas, sendo imprescindíveis para o fomento destes temas na academia.

No que se refere ao panorama dos pesquisadores, a Tabela 3 contempla os 108 pesquisadores identificados neste estudo, colocando em evidência os cinco autores mais profícuos, com suas respectivas IESs de origem. 
Tabela 3 - Principais autores e suas respectivas IESs

\begin{tabular}{lc}
\hline Autores / IES & Artigos \\
\hline Anwar Y / BINUS University & 2 \\
\hline Cvelbar LK / University of Ljubljana & 2 \\
\hline Galbreath J / Curtin University & 2 \\
\hline Lazonick W / INSEAD & 2 \\
\hline Mulyadi MS / BINUS University & 2 \\
\hline 103 autores publicaram 1 artigo & 1 \\
\hline Fonte: Dados da pesquisa. &
\end{tabular}

Os articulistas Anwar, Cvelbar, Galbreath, Lazonick e Mulyadi foram os que mais produziram artigos em 14 anos de estudos sobre os assuntos Governança Corporativa e Sustentabilidade em conexão, com dois artigos produzidos cada. Contudo, a maioria destes autores, isto é, 103, publicaram apenas uma vez. Ressalta-se também que dos cinco autores em realce, dois deles são vinculados a BINUS University. Tais dados evidenciam que os temas investigados em conjunto (Governança Corporativa e Sustentabilidade) ainda não se encontram em uma fase madura, devido ao fato de que muitos autores publicaram apenas uma vez, indo ao encontro do que foi contemplado na Tabela 2 e visualizado na Figura 2, que mostram respectivamente as autorias dos artigos e a rede de coautoria dos pesquisadores. Em suma, os assuntos ora em investigação não têm grupos de estudos consolidados até o momento. E isto pode ser explicado também pela incipiência dos temas publicados de maneira adjacente.

Em relação as IESs, a Tabela 4 descreve as 75 IESs identificadas neste estudo, realçando as oito com maior produtividade de papers.

Tabela 4 - Principais IESs e seus respectivos países de origem

\begin{tabular}{ll}
\hline IESs / País & Artigos \\
\hline Curtin University / Austrália & 3 \\
\hline University of Cambridge / Inglaterra & 3 \\
\hline BINUS University / Indonésia & 2 \\
\hline RMIT University / Austrália & 2 \\
\hline Universidad de Granada / Espanha & 2 \\
\hline University of Ljubljana / Eslovénia & 2 \\
\hline University of Massachusetts / EUA & 2 \\
\hline University of Oxford / Inglaterra & 2 \\
\hline 67 IESs publicaram 1 artigo & 1 \\
\hline Fonte: Dados da pesquisa. &
\end{tabular}


As Universidade de Curtin e Cambridge foram as que mais produziram artigos, três cada uma. Destacam-se ainda as IESs de BINUS, RMIT, Granada, Ljubljana, Massachusetts e Oxford, todas com dois artigos publicados. E destas oito IESs, duas são da Austrália, duas são da Inglaterra, e uma da Indonésia, Espanha, Eslovénia e Estados Unidos da América (EUA). Também é interessante notar que das 75 IESs identificadas neste trabalho, 67, ou seja, 89,33\%, publicaram apenas uma vez.

Já a Tabela 5 divulga as 26 nações identificadas nesta pesquisa, dando ênfase aos 12 países mais prolíficos.

Tabela 5 - Principais países e seus respectivos continentes

\begin{tabular}{ll}
\hline Países / Continente & Artigos \\
\hline Austrália / Oceania & 13 \\
\hline EUA / América do Norte & 11 \\
\hline Inglaterra / Europa & 10 \\
\hline Espanha / Europa & 4 \\
\hline África do Sul / África & 2 \\
\hline Canadá / América do Norte & 2 \\
\hline Eslovénia / Europa & 2 \\
\hline Holanda / Europa & 2 \\
\hline Índia / Ásia & 2 \\
\hline Indonésia / Ásia & 2 \\
\hline Itália / Europa & 2 \\
\hline Suíça / Europa & 2 \\
\hline 14 países publicaram 1 artigo & 1
\end{tabular}

A Austrália foi o país que se destacou neste estudo, publicando 13 trabalhos nos 14 anos de investigação. Em seguida vêm os EUA, Inglaterra e Espanha com 11, 10 e 4 artigos publicados concomitantemente. No que tange aos EUA e Inglaterra, estes resultados constatam a representatividade que estes países têm na Governança Corporativa (GRÜN, 2003), sobretudo também na literatura acadêmica internacional, quando coloca em evidência a Governança Corporativa com outros temas inerentes à mesma de maneira conjunta, como é o caso do assunto Estratégia (RIBEIRO, et al., 2013) e a temática Esporte (RIBEIRO; COSTA; FERREIRA, 2013). 
Logo após vêm as nações que publicaram dois artigos, que são: África do Sul, Canadá, Eslovénia, Holanda, Índia, Indonésia, Itália e Suíça. Destes países, seis são da Europa, dois são da América do Norte, dois da Ásia, um da Oceania e um da África. Contudo, apenas $53,85 \%$ dos países publicaram uma vez; tal resultado destoa um pouco dos resultados vistos dos autores e IESs.

Em seguida serão evidenciadas as Figuras de 2 a 6, que mostram as redes de coautoria, rede das IESs, rede das nações, rede dos autores e IESs em conjunto e a rede das IESs com a rede dos países juntas.

Figura 2 - Redes de coautoria

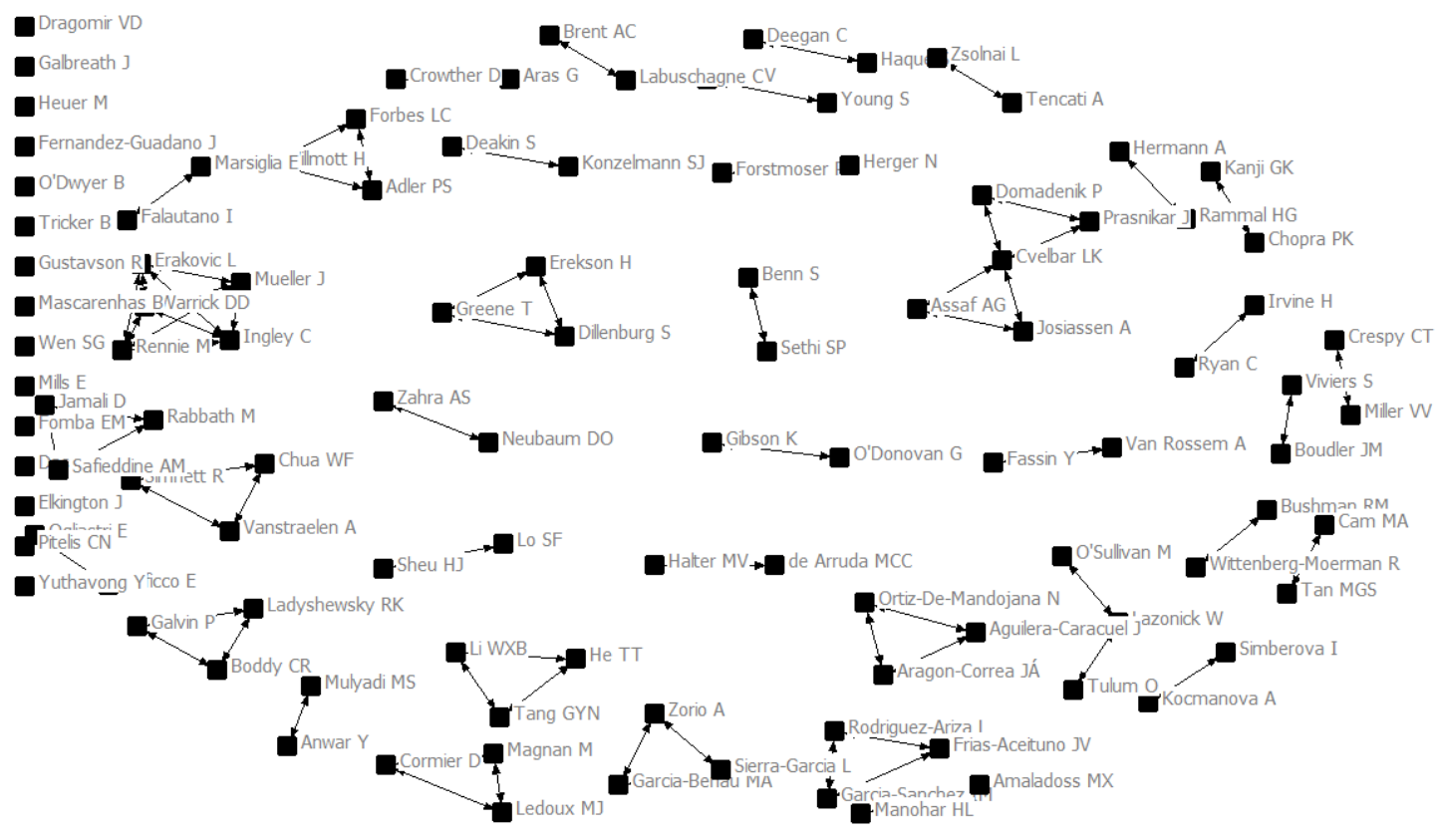

Fonte: Dados da pesquisa.

A Figura 2 mostra a rede de coautoria dos 108 pesquisadores envolvidos neste estudo, correspondendo automaticamente a 108 nós e 146 laços. Porém, esta rede encontra-se com baixa densidade, ou seja, 0,0128, o que pode ser em decorrência das publicações dos temas Governança Corporativa e Sustentabilidade juntos ainda estarem em uma fase imatura, influenciando na baixa interação entre os autores.

Observa-se que dos 108 articulistas, 15 publicaram sozinhos, 50 pesquisadores publicaram em par, 11 grupos de autores publicaram em trio, e 2 grupos de docentes publicaram em cinco. Estes dados vão ao encontro do que foi evidenciado na Tabela 2, mostrando assim a predominância das pesquisas publicadas em parceria. 
Já a Figura 3 visualiza a rede das 75 IESs identificadas neste trabalho, correspondendo a 75 nós e 74 laços.

Figura 3 - Redes das IESs

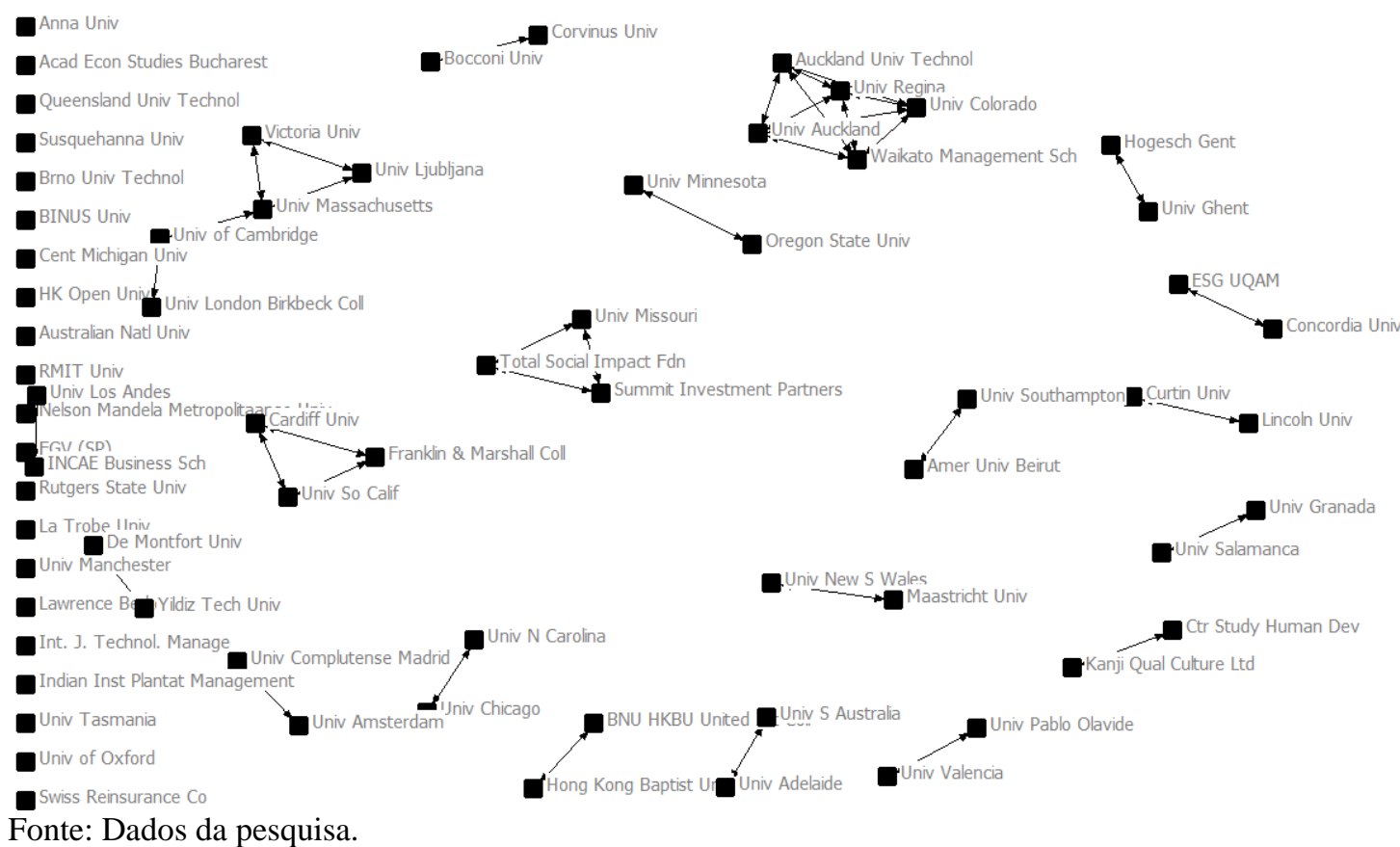

Como ocorrerá na rede dos autores, a rede social das IESs também se encontra com baixa densidade, isto é, 0,0133 , podendo ser em virtude da baixa conexão dos autores, influenciando na interação entre as instituições também. Analisando ainda a referida rede, pode-se constatar que 27 IESs publicaram sozinhas, 32 IESs publicaram em par, 2 grupos de IESs publicaram em trio, e outros 2 grupos publicaram em parceria de cinco. E um destes grupos encontra-se na Universidade de Cambridge, que porventura é uma das que mais publicou neste estudo.

Em relação à Figura 4, ela mostra a rede social dos países envolvidos neste estudo, que foram relacionados as IESs deste trabalho. 
Figura 4 - Redes dos países
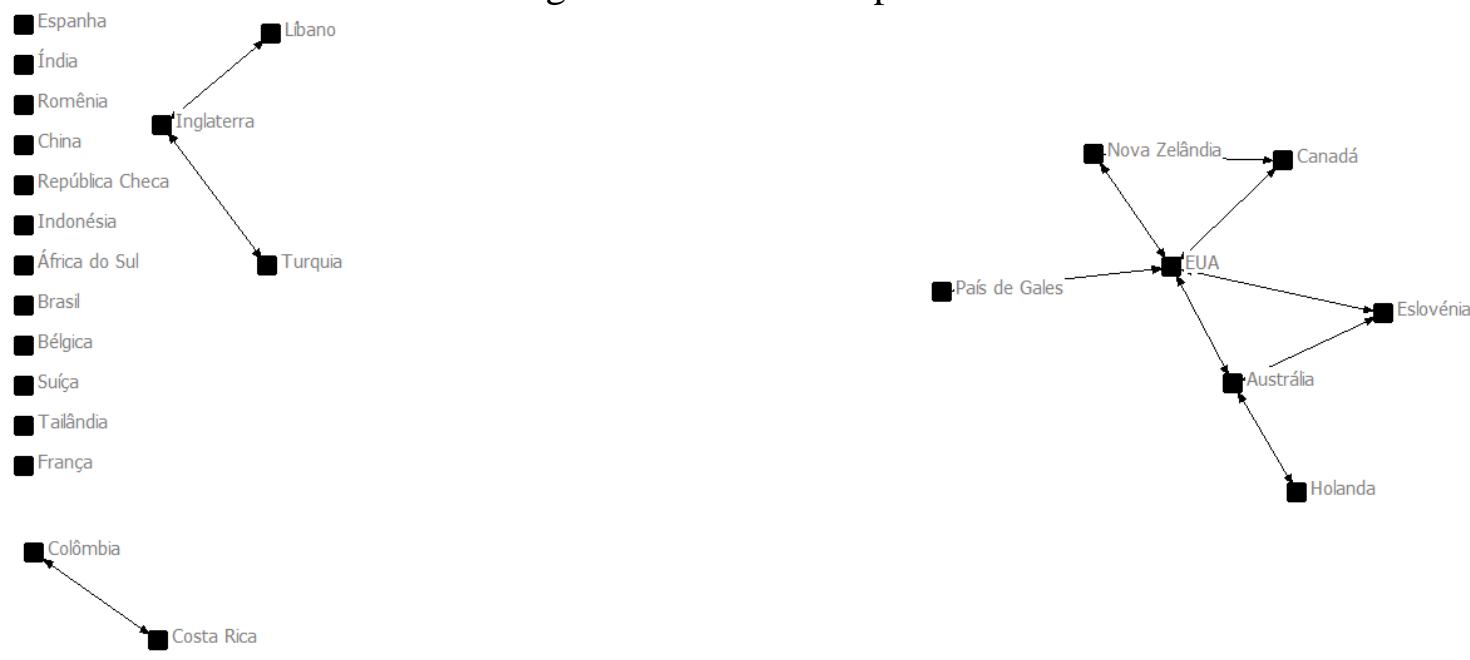

Fonte: Dados da pesquisa.

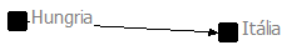

Avaliando a Figura 4, constatou-se que 12 países publicaram sozinhos, quatro publicaram em par, um grupo de nações publicaram em trio, e o maior grupo teve a interação de sete países. E destes encontram-se os EUA e Austrália como sendo os que obtiveram maior centralidade de grau, além de serem também os dois países que mais publicaram sobre os temas ora investigados.

Para complementar e fomentar as redes de coautoria e das IESs, foi construída uma rede two-mode, com estas duas redes sociais juntas. 
Figura 5 - Redes dos autores e IESs em conjunto

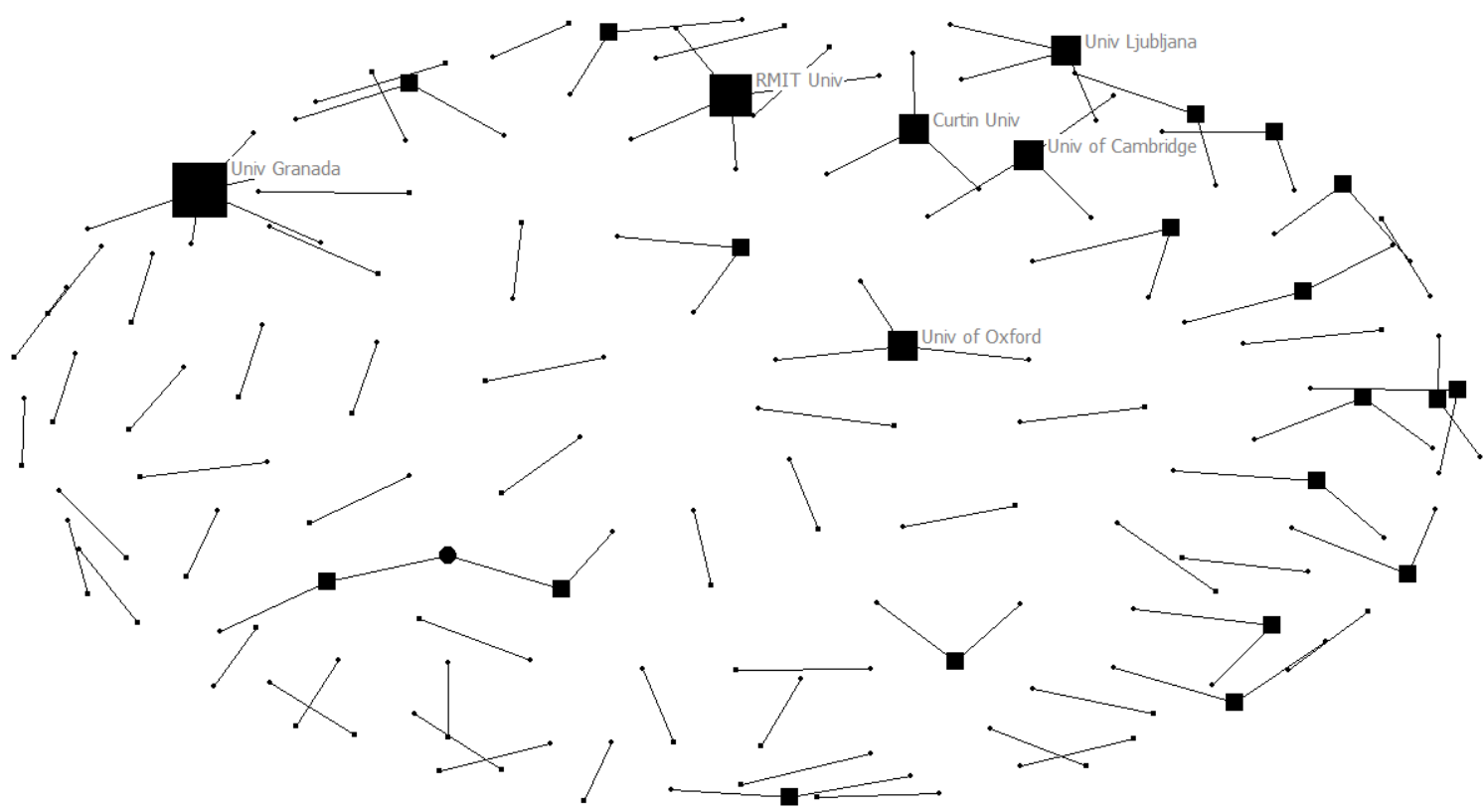

Fonte: Dados da pesquisa.

A Figura 5 realça a importância das Universidades de Granada, RMIT, Ljubljana, Cambridge, Oxford e Curtin, pois além de serem as IESs com maior quantidade de autores vinculados a elas, então entre as oito instituições que mais publicaram sobre as temáticas em investigação e isso é decorrente da quantidade de pesquisadores conectados a elas simultaneamente.

A Figura 6 realça mais uma rede two-mode, agora interagindo com as redes sociais dos países e das IESs. 
Figura 6 - Redes das IESs e países em conjunto
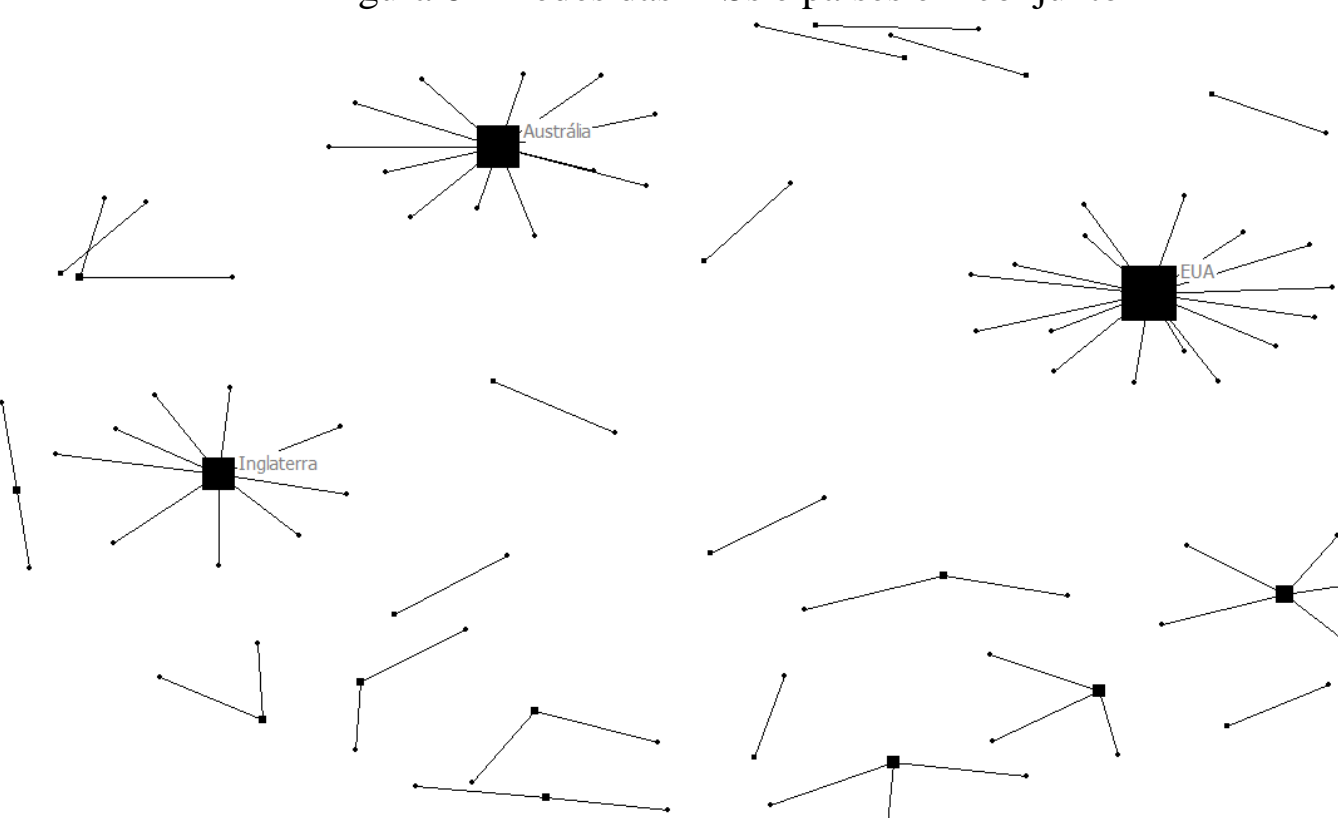

Fonte: Dados da pesquisa.

Explorando a Figura 6, verifica-se e ratifica-se a importância dos países EUA, Austrália e Inglaterra neste estudo, pois os três têm o maior número de IESs vinculados a eles, contribuindo assim para a proficuidade das três nações e da centralidade de grau dos EUA e Austrália nesta pesquisa.

No que se refere à Figura 7, ela mostra uma nuvem de todas as palavraschave dos 58 artigos investigados neste estudo.

Figura 7 - Palavras-chave

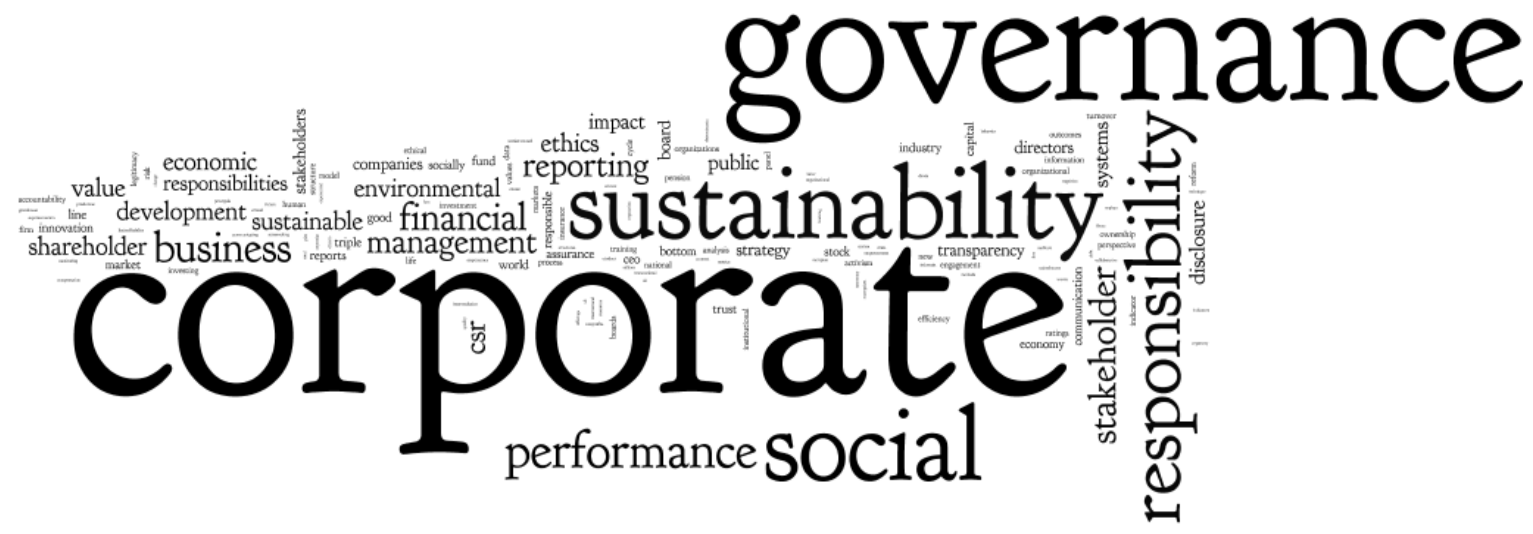

Fonte: Dados da pesquisa. 
Analisando a Figura 7, visualiza-se que as palavras: corporate, governance, sustainability, social, responsibility e performance, foram as mais vistas nos 58 artigos analisados. Este resultado vai ao encontro do que foi elencado na Tabela 6, que mostra os 22 temas identificados neste estudo.

Tabela 6 - Principais temas abordados

\begin{tabular}{|c|c|c|c|c|c|c|c|c|c|c|c|c|c|c|c|c|}
\hline Temas abordados/Anos & $\begin{array}{l}\mathbf{0} \\
\mathbf{0}\end{array}$ & $\begin{array}{l}0 \\
1\end{array}$ & $\begin{array}{l}\mathbf{0} \\
2\end{array}$ & $\begin{array}{l}\mathbf{0} \\
3\end{array}$ & $\begin{array}{l}0 \\
4\end{array}$ & $\begin{array}{l}\mathbf{0} \\
\mathbf{5}\end{array}$ & $\begin{array}{l}0 \\
6\end{array}$ & $\begin{array}{l}0 \\
7\end{array}$ & $\begin{array}{l}\mathbf{0} \\
8\end{array}$ & $\begin{array}{l}0 \\
9\end{array}$ & $\begin{array}{l}1 \\
\mathbf{0}\end{array}$ & $\begin{array}{l}1 \\
1\end{array}$ & $\begin{array}{l}1 \\
2\end{array}$ & $\begin{array}{l}1 \\
3\end{array}$ & $\begin{array}{c}\text { Tota } \\
1\end{array}$ & $\%$ \\
\hline $\begin{array}{l}\text { Responsabilidade Social } \\
\text { Corporativa }\end{array}$ & & & & & 1 & 2 & 1 & 1 & 1 & 4 & 3 & 1 & & 3 & 17 & 29,31 \\
\hline Disclosure & & & & 1 & & & & & & 1 & 1 & 3 & & & 6 & 10,34 \\
\hline Valor aos Acionistas & 1 & & & & 2 & & & & & 1 & & & 1 & & 5 & 8,62 \\
\hline Desempenho Organizacional & & & & & & & & & 2 & & & 1 & 1 & & 4 & 6,90 \\
\hline Conselho de Administração & & & & & & & & & & & 1 & 1 & 1 & & 3 & 5,17 \\
\hline Desenvolvimento Sustentável & & & & & & & 1 & 1 & & & & 1 & & & 3 & 5,17 \\
\hline Ética & & & & & & & & & & 1 & & 1 & 1 & & 3 & 5,17 \\
\hline Auditoria & & & & & & & & & & & & 2 & & & 2 & 3,45 \\
\hline Estrutura de Capital & & & & & & & 1 & & & & & & 1 & & 2 & 3,45 \\
\hline Accountability & & & & & & & & & & & & & 1 & & 1 & 1,72 \\
\hline CEO & & & & & & & & & & 1 & & & & & 1 & 1,72 \\
\hline Ciência e Tecnologia & & 1 & & & & & & & & & & & & & 1 & 1,72 \\
\hline Colaboração & & & & & & & & & & 1 & & & & & 1 & 1,72 \\
\hline Cultura organizacional & & & & & & & & & & 1 & & & & & 1 & 1,72 \\
\hline Gases de Efeito Estufa & & & & & & & & & & & & & & 1 & 1 & 1,72 \\
\hline Gestão Ambiental & & & & & & & & & & & & & 1 & & 1 & 1,72 \\
\hline Indicadores de Sustentabilidade & & & & & & & 1 & & & & & & & & 1 & 1,72 \\
\hline Inovação & & & & & & & & & & & & 1 & & & 1 & 1,72 \\
\hline IPO & & & & & & & & & & & & & 1 & & 1 & 1,72 \\
\hline Mudança Climática & & & & & & & & & & 1 & & & & & 1 & 1,72 \\
\hline Relatórios Ambientais & & & & & & & & 1 & & & & & & & 1 & 1,72 \\
\hline Triple Bottom Line & & & & & & & & & & & & & 1 & & 1 & 1,72 \\
\hline Total & 1 & 1 & $\mathbf{0}$ & 1 & 3 & 2 & 4 & 3 & 3 & $\begin{array}{l}1 \\
1\end{array}$ & 5 & $\begin{array}{l}1 \\
1 \\
\end{array}$ & 9 & 4 & 58 & $\begin{array}{c}100,0 \\
0\end{array}$ \\
\hline
\end{tabular}

Fonte: Dados da pesquisa.

Analisando a Tabela 6, nota-se que o tema Responsabilidade Social Corporativa foi o mais publicado nos 58 artigos estudados, aparecendo em realce em 17 papers. Em seguida vêm os temas: Disclosure, Valor aos Acionistas, Desempenho Organizacional, Conselho de Administração, Desenvolvimento Sustentável, Ética, 
Auditoria e Estrutura de Capital, com 6, 5, 4, 3, 3, 3, 2 e 2 artigos publicados respectivamente.

Nota-se que nove temáticas apareceram com publicações de duas a 17 vezes, como tema principal do manuscrito e a grande maioria dos temas só apareceu em um artigo cada, ou seja, 13 assuntos. É interessante notar também que dos 22 temas, 10 têm interação com o assunto Sustentabilidade, nove têm relação direta com o tema Governança Corporativa, e três relacionam-se com os dois temas.

De maneira geral, observou-se que o tema Governança Corporativa é um discurso dominante na literatura acadêmica (PINHEIRO; CARRIERI; JOAQUIM, 2013). Exemplo disso é sua relação intrínseca com outras temáticas, como a Gestão de Pessoas (SOUZA; BORBA, 2009), a Estratégia (RIBEIRO; MURITIBA; MURITIBA, 2012), a Estrutura de Propriedade (DAL VESCO; BEUREN, 2012) e o Esporte (RIBEIRO; COSTA; FERREIRA, 2013), por exemplo.

\section{Discussão e considerações finais}

O objetivo deste estudo foi mapear o perfil e a produção acadêmica dos temas Governança Corporativa e Sustentabilidade em conjunto, durante o período de 2000 a 2013. Para tanto, utilizou-se das técnicas de análise bibliométrica e de redes sociais. Mensurando as seguintes variáveis: produção acadêmica dos temas, periódicos de destaque, autoria, autores, IESs, países, redes de coautoria, redes das IESs, redes dos países, redes dos autores e IESs, redes das IESs e países, palavras-chave, e temas abordados.

Observou-se que os temas Governança Corporativa e Sustentabilidade, começaram a ser mais publicados de forma conjunta a partir do ano de 2006, alcançando seu ápice nos períodos de 2009 e 2011, com uma ligeira queda em 2012. Esta evolução das temáticas em conjunto a partir de 2006 pode ser em decorrência do surgimento do ISE, que trabalha justamente com os conceitos de Sustentabilidade, alicerçado pelos princípios de boas práticas de Governança Corporativa (BASSETTO, 2010).

Ressalta-se que este estudo explorou as temáticas de 2000 até 13 de setembro de 2013, ou seja, o referido ano ainda não foi fechado, sendo, importante sugestão para futuros estudos verificar como se portará o restante do ano corrente no 
que tange aos estudos dos assuntos mapeados. Heinzmann e Dreher (2012) corroboram similarmente com os achados.

Analisando os periódicos que se destacaram neste trabalho, tem-se o Corporate Governance: an International Review e o Journal of Business Ethics. Neste panorama, o estudos dos autores Huang e Ho (2011) e Ribeiro et al. (2013), confirmam a importância destes periódicos para a área de Governança Corporativa. Neste contexto, ressalta-se a acuidade destas revistas internacionais, indo ao encontro da que prega a Lei de Bradford, ou seja, a produtividade de periódicos nos temas ora estudados (PINHEIRO, 1983).

No que se refere à autoria, notou-se que a maioria das publicações são em parceria, sendo que a com dois autores se sobrepõe as demais. Tal resultado é confirmado mediante os estudos de: Duarte, Cardozo e Vicente (2012), Heinzmann e Dreher (2012), Catapan et al. (2013) e Souza e Ribeiro (2013). E dentre os pesquisadores destas autorias, destacaram-se cinco neste estudo; foram eles: Anwar, Cvelbar, Galbreath, Lazonick e Mulyadi, todos com dois artigos publicados, sendo que a maioria (103) publicou uma vez somente. Este fato remete à Lei de Lotka que enfoca na produtividade de autores, ou seja, poucos autores costumam publicar muito e muitos autores publicam pouco (CARDOSO et al., 2005).

E destes autores, o mais central foi Cvelbar, sendo assim considerado o mais importante da rede de coautoria (ROSSONI; GUARIDO FILHO, 2009). Realça-se que este fato vai ao encontro da baixa densidade da rede (CRUZ et al., 2011), ou seja, as interações entre os autores é pouca.

No que tange às IESs, enfatizam-se duas, as Universidade de Curtin e a de Cambridge, ambas com três manuscritos publicados neste estudo; porém, nenhuma destas encontra-se como instituições centrais deste estudo, destacou-se apenas a Universidade de Massachusetts, dentre aquelas que estão entre as oito mais profícuas deste trabalho. E estas três universidades destacadas aqui são dos países que mais publicaram artigos sobre os temas Governança Corporativa e Sustentabilidade juntos.

Neste panorama, ficaram em evidência os países: Austrália, EUA e Inglaterra, com 13, 11 e 10 papers publicados em 14 anos de estudos. A pesquisa dos autores Ribeiro et al. (2013) corroboram com estes achados, mostrando assim a 
importância destas nações com o debate intelectual sobre a Governança Corporativa em âmbito global (GRÜN, 2003).

Em relação às duas redes two-mode, elas retratam a rede de coautoria com a rede das IESs; e a rede das IESs com a rede dos países. A primeira demonstrou e ratificou a importância das Universidade de Curtin, Cambridge, RMIT, Granada, Ljubljana e Oxford, no contexto deste estudo, pois além de serem e estarem entre as oito IESs mais profícuas, também se destacaram como as que têm mais autores vinculados concomitantemente a elas. E a segunda rede também admitiu a importância dos países EUA, Austrália e Inglaterra neste trabalho, pois estão vinculados a eles o maior número de universidades.

A Lei de Zipf, que mensura a frequência de palavras (QUONIAM et al., 2001), foi enfatizada neste estudo, ao constatar que as palavras-chave corporate, governance, sustainability, social, responsibility e performance foram as mais vistas nos 58 artigos mapeados, sendo que tais palavras vão ao encontro dos temas abordados neste estudo.

No que se refere aos temas abordados, constatou-se que o assunto Responsabilidade Social Corporativa foi o mais publicado, aparecendo em 17 artigos como tema principal. É justificado, por entender que as organizações, sociedade e o Estado defendem tal fenômeno, pois ele delimita as ações empresariais (SCHROEDER; SCHROEDER, 2004), sendo também um dos principais princípios das boas práticas de Governança Corporativa (SILVA; REIS; AMÂNCIO, 2011).

O assunto Disclosure, foi o mais visto logo em seguida, publicado em seis manuscritos como tema principal. E é definido como toda a divulgação deliberada de informação da organização para o mercado de capitais, seja de natureza quantitativa ou qualitativa, requerida ou voluntária, por meio de canais formais ou informais (REITER; PROCIANOY, 2013), sendo considerado o tema que tem mais relação com a Governança Corporativa (CASTRO JUNIOR; CONCEIÇÃO; SANTOS, 2011).

O tema Valor aos Acionistas é outro vinculado ao assunto Governança Corporativa (STAUB; MARTINS; RODRIGUES, 2002; GUTTMANN, 2008), que apareceu como assunto em destaque em cinco publicações. Já o tema Desempenho Organizacional tem vínculo tanto com as boas práticas de governança (LOPES; 
BERNARDES; LARA, 2009), como também com a Sustentabilidade (SILVA; REIS; AMÂNCIO, 2011).

Em relação ao assunto seguinte, Conselho de Administração, que apareceu com ênfase em três artigos publicados, é considerado pauta relevante para a Governança Corporativa, tendo como objetivo proteger os acionistas mitigando expropriação (LEITE et al., 2013). Com isso, é considerado como um dos principais mecanismos de Governança Corporativa (SILVEIRA; BARROS; FAMÁ, 2003).

O tema Desenvolvimento Sustentável também se destacou, sendo publicado em três artigos. E o grande foco deste tema é manter a Sustentabilidade (PAULISTA; VARVAKIS; MONTIBELLER-FILHO, 2008). E o assunto Ética é outro que se vincula aos temas Governança Corporativa e Sustentabilidade (SILVA; REIS; AMÂNCIO, 2011).

A principal limitação deste estudo foi a busca pelos artigos somente por meio das duas palavras-chave, corporate governance e sustainability. Diante do exposto, sugere-se aumentar a quantidade de palavras-chave, podendo assim aumentar o número de publicações encontradas sobre as áreas investigadas. Sugere-se também fazer uma análise de conteúdo sobre os 22 temas analisados, podendo assim melhor compreender a importância dos mesmos para os temas Governança Corporativa e Sustentabilidade. Outra sugestão é otimizar as análises da bibliometria e das redes sociais, ou seja, utilizar não só as estatísticas descritivas, mas também análise multivariadas de dados e outros atributos de Análise de Redes Sociais, como, por exemplo, análise de intermediação e de proximidade. 


\section{Referências}

ÁLVARES, E.; GIACOMETTI, C.; GUSSO, E. Governança corporativa: um modelo brasileiro. Access Online via Elsevier, 2008.

ARAS, G.; CROWTHER, D. Governance and Sustainability: an Investigation into the Relationship between Corporate Governance and Corporate Sustainability. Management Decision, USA, v. 46, n. 3, p. 433-448, 2008.

BASSETTO, L. I. A incorporação da responsabilidade social e Sustentabilidade: um estudo baseado no relatório de gestão 2005 da companhia paranaense de energia COPEL. Gestão \& Produção, São Paulo, v. 17, n. 3, p. 639-651, 2010.

BERARDI, P. C. A evolução do conceito de Governança Corporativa à luz da ética: uma análise longitudinal. 2008. 149 p. Dissertação (Mestrado em Administração de Empresas) - Fundação Getulio Vargas, São Paulo, 2008.

BERTUCCI, J. L. de O.; BERNARDES, P.; BRANDÃO, M. M. Políticas e práticas de Governança Corporativa em empresas brasileiras de capital aberto. Revista de Administração da USP, São Paulo, v. 41, n. 2, p. 183-196, 2006.

BEUREN, I. M.; SOUZA, J. C. de. Em busca de um delineamento de proposta para classificação dos periódicos internacionais de contabilidade para o Qualis Capes. Revista Contabilidade \& Finanças, São Paulo, v. 19, n. 46, p. 44-58, 2008.

CARDOSO, R. L. et al. Pesquisa científica em contabilidade entre 1990 e 2003. Revista de Administração de Empresas, São Paulo, v. 45, n. 2, p. 34-45, 2005.

CASTRO JUNIOR, F. H. F. de; CONCEIÇÃO, P. M. da; SANTOS, D. A. A relação entre o nível voluntário de transparência e o custo de capital próprio das empresas brasileiras não-financeiras. Revista Eletrônica de Administração, Rio Grande do Sul, v. 17, n. 3, p. 617-635, 2011.

CATAPAN, A.; CHEROBIM, A. P. M. S. Estado da arte da Governança Corporativa: estudo bibliométrico nos anos de 2000 a 2010. Revista de Administração, Contabilidade e Economia, Santa Catarina, v. 9, n. 1-2, p. 207-230, 2011. 
CATAPAN, A. et al. Sustentabilidade: uma investigação da produção científica brasileira no período de 2001 à 2011. Revista da Faculdade de Administração e Economia, São Paulo, v. 4, n. 2, p. 187-202, 2013.

COELHO, A. C. D.; LOPES, A. B. Avaliação da prática de gerenciamento de resultados na apuração de lucro por companhias abertas brasileiras conforme seu grau de alavancagem financeira. Revista de Administração Contemporânea, São Paulo, v. 11, n. spe2, p. 121-144, 2007.

COSTA, G. da S.; BOENTE, D. R. Análise do perfil da produção científica sobre ciclo de vida no período de 2000 a 2011. Revista Ambiente Contábil, Rio Grande do Norte, v. 4, n. 1, p. 106-119, 2012.

CRUZ, A. P. C. da et al. Perfil das redes de cooperação científica: Congresso USP de Controladoria e Contabilidade - 2001 a 2009. Revista Contabilidade \& Finanças, São Paulo, v. 22, n. 55, p. 64-87, 2011.

DA CUNHA, P. R.; MOURA, G. D.; SANTANA, A. G. Perfil dos estudos sobre o tema Governança Corporativa publicados em periódicos brasileiros de 2009 a 2011. Registro Contábil, Alagoas, v. 4, n. 2, p. 105-122, 2013.

DAL VESCO, D. G.; BEUREN, I. M. Teoria da estrutura de propriedade: redes sociais em periódicos internacionais de alto impacto. Revista Facultad de Ciencias Económicas: Investigación y Reflexión, Colombia, v. 20, n. 1, 2012.

DUARTE, E.; CARDOZO, M. A.; VICENTE, E. F. R. Governança: uma investigação da produção científica brasileira no período de 2000 a 2009. Contabilidade, Gestão e Governança, Brasília, v. 15, n. 1, p. 115-127, 2012.

DURISIN, B.; PUZONE, F. Maturation of Corporate Governance Research, 1983-2007: an Assessment. Corporate Governance: An International Review, USA, v. 17, n. 3, p. 266-291, 2009.

ELKINGTON, J. Governance for Sustainability. Corporate Governance: An International Review, USA, v. 14, n. 6, p. 522-529, 2006.

GABRIELE, P. D.et al. Sustentabilidade e vantagem competitiva estratégica: um estudo exploratório e bibliométrico. Revista Produção Online, Santa Catarina, v. 12, n. 3, p. 729-755, 2012. 
GALlON, A. V.; ENSSLIN, S. R. Evidenciação estratégica dos pilares da Sustentabilidade empresarial: investigação no relatório da administração das empresas que compõem o ISE. Pensar Contábil, Rio de Janeiro, v. 10, n. 41, p. 1-12, 2008.

GRÜN, R. Atores e ações na construção da Governança Corporativa brasileira. Revista Brasileira de Ciências Sociais, São Paulo, v. 18, n. 52, p. 139-161, 2003.

GUTTMANN, R. Uma introdução ao capitalismo dirigido pelas finanças. Novos Estudos -

CEBRAP, São Paulo, n. 82, p. 11-33, 2008.

HEINZMANN, L. M.; DREHER, M. T. Governança corporativa e Sustentabilidade: a produção científica está abordando os temas de forma articulada? Revista de Administração e Negócios da Amazônia, Amazonas, v. 4, n. 1, p. 1-12, 2012.

HENRIQUES, F. E.; SELIG, P. M.; MIGUEL, P. A. C. Modularidade e custos: seleção de um referencial para pesquisa por meio de uma análise bibliométrica. ABCustos Associação Brasileira de Custos, Rio Grande do Sul, v. 7, n. 2, 2012.

HUANG, C. Y.; HO, Y. S. Historical Research on Corporate Governance: a Bibliometric Analysis. African Journal of Business Management, Nigeria, v. 5, n. 2, p. 276-284, 2011.

IGARASHI, W. et al. Investigação no contexto brasileiro sobre gestão do conhecimento/aprendizagem/tecnologia de informação: pesquisa realizada na Scientific Electronic Library Online. Cadernos EBAPE.BR, Rio de Janeiro, v. 6, n. 2, p. 1-18, 2008 .

JABBOUR, C. J. C.; JABBOUR, A. B. L. de S; OLIVEIRA, J. H. C. de.; CALDEIRA, J. H. The Perception of Brazilian Researchers Concerning the Factors that Influence the Citation of their Articles: a study in the Field of Sustainability. Serials Review, USA, v. 39, n. 2, p. 93, 2013.

KOCMANOVÁ, A.; HŘEBÍČEK, J.; DOČEKALOVÁ, M. Corporate Governance and Sustainability. Economics and Management, Reino Unido, v. 16, p. 543-550, 2011. 
LEAL, R. P. C.; SAITO, R. Finanças corporativas no Brasil. RAE-eletrônica, São Paulo, v. 2, n. 2, p. 1-15, 2003.

LEITE, D. A.et al. Pesquisa em Governança Corporativa no Brasil: análise teórica e agenda de pesquisa à luz da dimensão holística da Governança Corporativa de 1998 a 2010. Revista Tecer, Minas Gerais, v. 6, n. 10, p. 62-79, 2013.

LOPES, H. E. G.; BERNARDES, P.; LARA, L. de C. Governança corporativa e desempenho: um estudo em empresas de capital aberto no Brasil. Revista Economia \& Gestão, Minas Gerais, v. 19, n. 19, p. 26-43, 2009.

MACHADO JÚNIOR, C. et al. Estudo bibliométrico da Sustentabilidade ambiental: os 15 anos do simpósio de administração da produção, logística e operações internacionais - Simpoi. J Health Sci Inst, São Paulo, v. 31, n. 2, p. 123-131, 2013.

MALACRIDA, M. J. C.; YAMAMOTO, M. M. Governança corporativa: nível de evidenciação das informações e sua relação com a volatilidade das ações do Ibovespa. Revista Contabilidade \& Finanças, São Paulo, v. spe, p. 65-79, 2006.

MATHEUS, R. F.; SILVA, A. B. de O. Análise de redes sociais como método para a Ciência da Informação. DataGramaZero-Revista de Ciência da Informação, Brasília, v. 7, n. 2, 2006.

MICHELON, G.; PARBONETTI, A. The Effect of Corporate Governance on Sustainability Disclosure. Journal of Management \& Governance, USA, v. 16, n. 3, p. 477-509, 2012.

MIZRUCHI, M. S. Análise de redes sociais: avanços recentes e controvérsias atuais. Revista de Administração de Empresas, São Paulo, v. 46, n. 3, p. 72-86, 2006.

NUNES, J. G. et al. Análise das variáveis que influenciam a adesão das empresas ao índice BM\&F Bovespa de Sustentabilidade empresarial. Revista de Administração e Contabilidade da Unisinos, Rio Grande do Sul, v. 7, n. 4, p. 328-340, 2010.

PAULISTA, G.; VARVAKIS, G.; MONTIBELLER-FILHO, G. Espaço emocional e indicadores de Sustentabilidade. Ambiente \& Sociedade, São Paulo, v. 11, n. 1, p. 185 200, 2008. 
PINHEIRO, A. S.; CARRIERI, A. de P.; JOAQUIM, N. de F. Esquadrinhando a Governança Corporativa: o Comportamento dos Personagens sob o Ponto de Vista dos Discursos dos Autores Acadêmicos. Revista Contabilidade \& Finanças, São Paulo, v. 24, n. 63, p. 231-242, 2013.

PINHEIRO, L. V. R. Lei de Bradford: uma reformulação conceitual. Ciência da Informação, Brasília, v. 12, n. 2, p. 59-80, 1983.

QUONIAM, L. et al. Inteligência obtida pela aplicação de data mining em base de teses francesas sobre o Brasil. Ciência da Informação, Brasília, v. 30, n. 2, p. 20-28, 2001.

REITER, N.; PROCIANOY, J. L. Impacto informacional das reuniões públicas APIMEC: um estudo de evento. Revista de Administração Mackenzie, São Paulo, v. 14, n. 2, p. 127-154, 2013.

RIBEIRO, H. C. M.et al. Entender para progredir: análise da pesquisa em Governança Corporativa no Brasil. Gestão Contemporânea, Rio Grande do Sul, v. 9, n. 12, p. 1142, 2012a.

RIBEIRO, H. C. M. et al. Governança corporativa: um estudo bibliométrico da produção científica das dissertações e teses brasileira. Contabilidade, Gestão e Governança, Brasília, v. 15, n. 3, p. 52-70, 2012b.

RIBEIRO, H. C. M.; MURITIBA, S. N.; MURITIBA, P. M. Perfil e crescimento dos temas "Governança Corporativa" e "estratégia": uma análise dos últimos 11 anos nos periódicos da área de administração no Brasil. Gestão \& Regionalidade, São Paulo, v. 28, n. 82, p. 83-99, 2012.

RIBEIRO, H. C. M.; COSTA, B. K.; FERREIRA, M. P. Governança corporativa nos esportes: Uma análise dos últimos 23 anos de produção acadêmica em periódicos internacionais. In: SEMINÁRIOS EM ADMINISTRAÇÃ̃O, 2013, São Paulo. Anais... São Paulo: SemeAd, 2013.

RIBEIRO, H. C. M. et al. Mapeando os temas estratégia e Governança Corporativa: uma análise dos últimos 23 anos de estudo nos periódicos internacionais da área de administração. In: ENCONTRO DE ESTUDOS EM ESTRATÉGIA, 2013, Bento Gonçalves. Anais... Rio Grande do Sul: 3Es, 2013. 
ROCZANSKI, C. R. M. et al. O estado da arte em estratégia na Revista de Administração Contemporânea: um estudo bibliométrico. Revista Economia e Gestão, Minas Gerais, v. 10, n. 24, p. 28-47, 2010.

ROMO-FERNÁNDEZ, L. M.; GUERRERO-BOTE, V. P.; MOYA-ANEGÓN, F. World Scientific Production on Renewable Energy, Sustainability and the Environment. Energy for Sustainable Development, USA, v. 16, n. 4, p. 500-508, 2012.

ROSSONI, L. et al. Cooperação interinstitucional no campo da pesquisa em estratégia. Revista de Administração de Empresas, São Paulo, v. 47, n. 4, p. 1-15, 2007.

ROSSONI, L.; HOCAYEN-DA-SILVA, A. J. Cooperação entre pesquisadores da área de administração da informação: evidências estruturais de fragmentação das relações no campo científico. Revista de Administração da USP, São Paulo, v. 43, n. 2, p. 138$151,2008$.

ROSSONI, L.; GUARIDO FILHO, E. R. Cooperação entre programas de pósgraduação em administração no Brasil: evidências estruturais em quatro áreas temáticas. Revista de Administração Contemporânea, São Paulo, v. 13, n. 3, p. 366-390, 2009.

SAMPAIO, R. R.; ROSA, C. P.; PEREIRA, H. B. de B. Mapping Information and Knowledge Flow: IT Governance from the Perspective of Social Networks. Gestão \& Produção, São Paulo, v. 19, n. 2, p. 377-387, 2012.

SCHMITT, C. da S.; HAYDE, C. T. von der; DREHER, M. T. Sustentabilidade como vantagem competitiva: uma análise bibliométrica. Estratégia \& Negócios, Rio Grande do Sul, v. 6, n. 2, p. 157-174, 2013.

SCHOOLMAN, E. D. et al. How Interdisciplinary is Sustainability Research? Analyzing the Structure of an Emerging Scientific Field. Sustainability science, USA, v. 7, n. 1, p. 67-80, 2012.

SCHROEDER, J. T.; SCHROEDER, I. Responsabilidade social corporativa: limites e possibilidades. RAE-eletrônica, São Paulo, v. 3, n. 1, p. 1-10, 2004.

SILVA, S. S. da; REIS, R. P.; AMÂNCIO, R. Paradigmas ambientais nos relatos de Sustentabilidade de organizações do setor de energia elétrica. Revista de Administração Mackenzie, São Paulo, v. 12, n. 3, p. 146-176, 2011. 
SILVEIRA, A. D. M. da; BARROS, L. A. B. de C.; FAMÁ, R. Estrutura de governança e valor das companhias abertas brasileiras. Revista de Administração de Empresas, São Paulo, v. 43, n. 3, p. 50-64, 2003.

SOUZA, F. C.; BORBA, J. A. Governança corporativa e remuneração de executivos: uma revisão de artigos publicados no exterior. Contabilidade Vista \& Revista, Minas Gerais, v. 18, n. 2, p. 35-48, 2009.

SOUZA, F. J. V. de; SILVA, M. C. da; ARAUJO, A. O. Uma análise da produção científica da área de contabilidade governamental nos periódicos que utilizam o SEER e o Scielo. In: CONGRESSO USP DE INICIAÇÃO CIENTÍFICA EM CONTABILIDADE, 9, 2012, São Paulo. Anais... São Paulo: CICC-USP, 2012.

SOUZA, M. T. S. de; RIBEIRO, H. C. M. Sustentabilidade ambiental: uma metaanálise da produção brasileira em periódicos de administração. Revista de Administração Contemporânea, São Paulo, v. 17, n. 3, p. 368-396, 2013.

SROUR, R. H. Por que empresas eticamente orientadas? Revista Organicom, São Paulo, v. 5, n. 8, p. 59-67, 2011.

STAUB, I. D.; MARTINS, H. C.; RODRIGUES, S. B. Governança corporativa e criação de valor para o acionista: da teoria à prática, os impactos organizacionais e financeiros. Revista Economia \& Gestão, Minas Gerais, v. 2, n. 3, p. 36-55, 2002.

STEINBERG, H. Governança Corporativa. São Paulo: Editora Gente, 2008.

TERRA, P. R. S.; LIMA, J. B. N. de. Governança corporativa e a reação do mercado de capitais à divulgação das informações contábeis. Revista Contabilidade \& Finanças, São Paulo, n. 42, p. 33-49, 2006.

YARIME, M.; TAKEDA, Y.; KAJIKAWA, Y. Towards Institutional Analysis of Sustainability Science: a Quantitative Examination of the patterns of Research Collaboration. Sustainability Science, USA, v. 5, n. 1, p. 115-125, 2010. 